\title{
Histiocytosis X
}

\author{
Follow-up of 43 cases
}

\author{
D. G. SIMS
}

From the Department of Child Health, University of Newcastle upon Tyne

SUMMARY Over a 29-year period, 43 cases of histiocytosis X presented in children under the age of 12 years. 29 patients $(67 \%)$ have survived, and of these, $15(52 \%)$ have a detectable disability. It was confirmed that young age at presentation and evidence of soft tissue involvement were associated with a worse prognosis. The majority of deaths were associated with pulmonary involvement. 14 patients developed diabetes insipidus. 5 of the surviving adults have heights below the 3rd centile. Puberty usually occurred at a normal age.

Follow-up studies on 12 survivors showed no evidence of residual abnormality of haematology, deficient lymphocyte function, or yeast opsonization. HLA typing showed no unusual pattern. Mild carbon monoxide diffusion defects were present in 4 patients and other abnormalities were detected on lung function tests.

Histiocytosis X (Letterer-Siwe disease, HandSchüller-Christian disease, and eosinophilic granuloma of bone) is an uncommon condition in childhood and any one paediatrician is likely to see few cases. A survey in the north-east of England was undertaken to follow-up cases which have presented before the age of 12 years in this area during the years 1947-1975 inclusive. The study was done with two objects. Firstly to determine the clinical spectrum of illness and its progression in a group with all degrees of severity, most of them occurring in the years when steroid and cytotoxic therapy was not in use, and secondly to gain some information about the children's development as they grew up, the spectrum of their residual disabilities, and what became of them in young adult life. Also markers were sought which may have predisposed some of these children to this condition.

\section{Method}

Cases of Letterer-Siwe disease, Hand-SchüllerChristian disease, and eosinophilic granuloma of bone (single or multiple) were sought by checking through Newcastle hospitals' admissions books and other hospital diagnostic records systems, contacting consultant paediatricians for cases under their care in more recent years, and then examining medical notes and microfilm records for fuller details.

Received 17 September 1976
Regional paediatricians were contacted about children under their care. Requests for information were also made to the Newcastle hospitals' departments of radiotherapy, orthopaedics, and ear, nose, and throat surgery in case any children had been treated solely by these departments.

Survivors were traced and most either were seen personally for follow-up, if still living near to Newcastle, or were asked to complete a questionnaire, modified slightly to take account of each patient's original complaint. If more distant cases were still under the care of local paediatricians, their up-to-date medical records were used, and in older patients information was obtained from the family doctor. 14 survivors aged 5-26 years were seen personally for follow-up and, of these, 12 were agreeable to further investigations. Haematological, biochemical, immunological, and pulmonary function investigations were performed.

\section{Results}

During both halves of the study period most cases came from the larger towns and cities with scattered cases occurring in rural areas. 2 children, both of whom died, came from outside the study area but are included in this review (one came from South Africa in 1949, and one from East Anglia in 1972).

Using father's occupation as a guide to social class in the 35 cases where this information was available, 5 children came from social classes I and II 


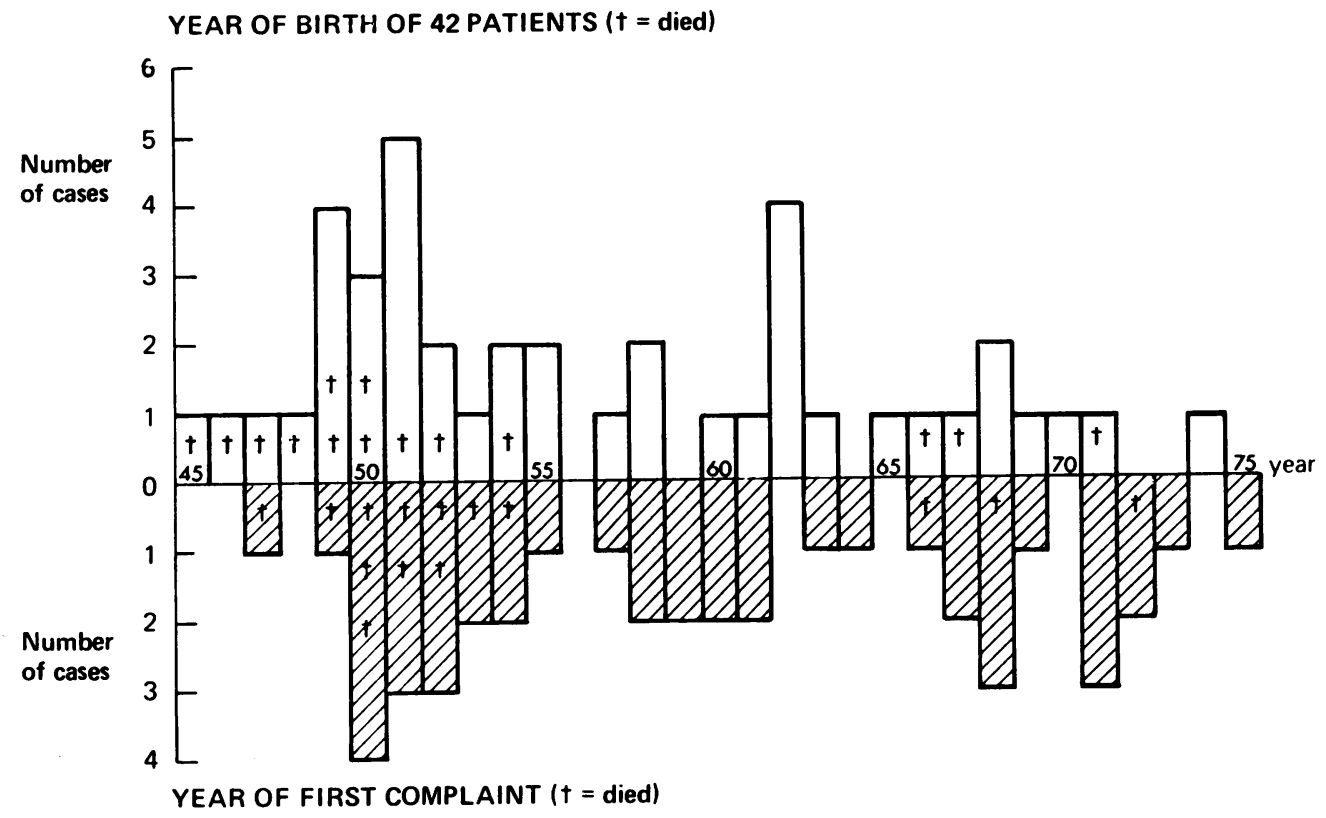

Fig. Year of birth and year of first complaint in 42 cases of histiocytosis $X$.

( $14 \%), 20$ children from social class III $(57 \%)$, and 10 from social classes IV, V, or unemployed (29\%). Figures for the study area from the census of 1951 show that $18 \%$ of the population came from social classes I and II, $49 \%$ from social class III, and $33 \%$ from social classes IV and V.

The years of birth and the approximate years of first symptoms of histiocytosis $X$ for the $\mathbf{4 2}$ children where this information is available are shown, together with the outcome, in the Fig. The ages of the children at the time of the initial complaint are shown in Table 1.23 patients were male and 20 female. 8 males and 6 females died, more in the late 1940 s and early 1950 s than since.

Twenty-nine patients $(67 \%)$ have survived and 28 have been traced. For this group the mean age of onset was approximately $\mathbf{4 7}$ months (range, birth to 10 years) and to the time of follow-up the mean length of survival was approximately $12 \frac{1}{2}$ years (range 8 months to 25 years). One patient of the 14 who died committed suicide aged $25 \frac{1}{2}$ years. If he is excluded, the mean age of onset of the remainder who died was approximately 15 months (range, birth to 43 months), the mean duration of illness approximately 13 months (range 2 months -4 years), and the mean age at death 28 months (range 2 months -4 years).

Clinical features. As with any disease which can affect several body systems, the initial clinical features and later progression of the disease varied widely. The features at presentation in the survivors and those dying are listed in Table 2. The survivors presented with more skeletal complaints, such as bone pain and swelling, and fewer general features of ill health such as anorexia and failure to gain weight, fewer skin manifestations, and less lymphadenopathy than those who eventually died. Lumps on the skull were a common presenting feature in the survivors. None of those who died presented with dyspnoea, hepatosplenomegaly, or thirst and polyuria.

Table 1 Age at time of first symptoms and signs

\begin{tabular}{|c|c|c|c|c|c|c|c|c|c|c|c|}
\hline & \multirow[b]{2}{*}{ Birth } & \multicolumn{2}{|c|}{ Months } & \multicolumn{8}{|c|}{ Years } \\
\hline . & & $<6$ & $<12$ & $1+$ & $2+$ & $3+$ & $4+$ & $5+$ & $6+7$ & $8+9$ & $10+11$ \\
\hline $\begin{array}{l}\text { Total cases } \\
\text { Deaths }\end{array}$ & $\begin{array}{l}1 \\
1\end{array}$ & $\begin{array}{l}3 \\
1\end{array}$ & $\begin{array}{l}5 \\
4\end{array}$ & $\begin{array}{l}9 \\
3\end{array}$ & $\begin{array}{r}11 \\
2\end{array}$ & $\begin{array}{l}2 \\
2\end{array}$ & $\begin{array}{l}3 \\
1 \\
\text { suicide }\end{array}$ & - & 2 & 4 & ${ }^{3}-$ \\
\hline
\end{tabular}


Table 2 Symptoms and signs at presentation

\begin{tabular}{lll}
\hline & $\begin{array}{l}\text { Survivors } \\
n=29(\%)\end{array}$ & $\begin{array}{l}\text { Deaths } \\
n=14(\%)\end{array}$ \\
\hline Symptoms & $4(14)$ & $5(36)$ \\
Anorexia & $2(7)$ & $4(29)$ \\
Listlessness & $2(7)$ & $4(29)$ \\
Failure to gain weight & $13(45)$ & $4(29)$ \\
Bone pain & $-2(14)$ \\
Discharging ears & $2(7)$ & $1(7)$ \\
Cough & $1(4)$ & $1(7)$ \\
Toothache & $4(14)$ & - \\
Limp & $1(4)$ & - \\
Earache & - & \\
Refusal to walk & & $5(36)$ \\
Signs & $3(10)$ & $5(36)$ \\
Skin rash & $6(21)$ & - \\
Generalized or local & $5(17)$ & - \\
lymphadenopathy & $7(24)$ & - \\
Lump behind ear & $4(14)$ & - \\
Lump elsewhere on skull & $3(10)$ & - \\
Hepatomegaly & $3(10)$ & - \\
Pallor & $2(7)$ & - \\
Petechiae & $2(7)$ & - \\
Splenomegaly & $1(4)$ & - \\
Limb swelling & $1(4)$ & - \\
Pathlogical fracture & $1(4)$ & - \\
Proptosis & & \\
Papilloedema & & \\
\hline
\end{tabular}

Table 3 summarizes the features which developed during the course of the illnesses in the two groups while under hospital follow-up and treatment. The clinical features of pulmonary disease were confined almost entirely to those who died. Hepatomegaly developed in $50 \%$ of those who died and in only $4 \%$ of the survivors, giving an overall of $17 \%$ survivors with hepatomegaly at some stage in the illness. 10 survivors $(35 \%)$ developed diabetes insipidus -2 of them only temporarily. After presentation, no survivor went on to develop a lump behind the ear and yet $11(38 \%)$ developed multiple bony lesions. Every survivor finished up with one or more bone lesions, 10 having a solitary lesion (5

Table 3 Clinical features developing after presentation

\begin{tabular}{lll}
\hline & $\begin{array}{l}\text { Survivors (29) } \\
\%\end{array}$ & $\begin{array}{l}\text { Deaths (14) } \\
\%\end{array}$ \\
\hline $\begin{array}{lll}\text { Multiple progressive bone } \\
\text { lesions }\end{array}$ & $11(38)$ & $2(14)$ \\
Diabetes insipidus & $10(35)$ & $4(29)$ \\
Splenomegaly & $5(17)$ & $2(14)$ \\
Deafness & $5(17)$ & - \\
Increasing lymphadenopathy & $3(10)$ & $5(36)$ \\
Pathological fracture & $2(7)$ & - \\
Dyspnoea & $2(7)$ & $9(64)$ \\
Cyanosis & $2(7)$ & $9(64)$ \\
Rales & $2(7)$ & $5(36)$ \\
Proptosis & $2(7)$ & $2(14)$ \\
Hepatomegaly & $1(4)$ & $7(50)$ \\
Facial palsy & $1(4)$ & - \\
Pneumothorax & - & $3(21)$ \\
Clubbing & - & $2(14)$ \\
Petechiae & - & $4(29)$ \\
Paraplegia & - & $1(7)$ \\
Discharging ears & - & \\
\hline
\end{tabular}

in the skull, 3 in lumbar vertebrae, and 2 in limb bones). Overall, the most common bone mass at presentation was in the frontal bone (7 cases), followed by spinal lesions (6) and humerus (5). Table 4 shows the distribution of bone lesions throughout the illnesses. 20 of the survivors $(69 \%)$ had skull lesions at one time or another compared with $7(50 \%)$ of those who died.

Table 4 Distribution of bone lesions

\begin{tabular}{lll}
\hline & Survivors (29) & Deaths (14) \\
\hline Total with skeletal lesions & 29 & 8 \\
Skull vault and base & 20 & 7 \\
Maxilla & 2 & 1 \\
Mandible & 3 & - \\
Clavicle & 1 & 1 \\
Scapula & - & 2 \\
Humerus & 7 & 3 \\
Ribs & 6 & 3 \\
Spine & 6 & 3 \\
Pelvis & 8 & 4 \\
Femur & 7 & - \\
Tibia & 3 & - \\
Fibula & 2 & - \\
Foot bones & 4 & \\
\hline
\end{tabular}

Radiological findings. All survivors had abnormal bone $x$-rays at some time during their illness, whereas 6 of those dying had no radiological or necropsy evidence of bone involvement. 24 survivors had chest $x$-rays, and of these, 15 were normal. 2 of the remainder showed miliary mottling, 3 widespread infiltration (with associated 'honeycombing' in 1), 1 a healed primary tuberculous complex some years after onset, 1 increased basal lung markings, 1 retrocardiac pulmonary collapse, and 1 intercurrent pneumonia. 4 of the children who died each had only one chest $x$-ray performed and this was normal. The remainder had abnormalities on their initial film, which remained static or progressed. The most common appearance was very like miliary tuberculosis with the later development of widespread reticulation. 3 patients developed pneumothoraces, 2 of them terminally and bilaterally, 2 had paramediastinal lymphadenopathy, and 1 had 'honeycombing' of the lung fields.

Table 5 gives results of other investigations. Neither child with a positive Mantoux was considered at the time to have tuberculosis and was not treated as such. One of them was shown to have a healed primary focus on chest $x$-ray some years later. Even with active bone lesions, the ESR was not always raised, the range being $2-91 \mathrm{~mm} / \mathrm{h}$.

Histological and necropsy findings. Biopsy material was obtained in 24 survivors. Bone lesions were the most frequently sampled. In 11 children the histological diagnosis was of definite eosinophilic granuloma of bone, but in the remaining 13 the 
Table 5 Findings on laboratory testing

\begin{tabular}{lcc} 
& Survivors (29) & Deaths (14) \\
\hline $\begin{array}{lcc}\text { Anaemia }(\mathrm{Hb} \leqslant 10 \mathrm{~g} / \mathrm{dl}) \\
\text { Total WBC } \geqslant 10000 / \mathrm{mm}^{3}\end{array}$ & 8 & 4 \\
$\begin{array}{l}\text { Nucleated RBC in peripheral } \\
\text { blood }\end{array}$ & 1 & 10 \\
$\begin{array}{l}\text { Primitive WBC in peripheral } \\
\text { blood }\end{array}$ & - & - \\
$\begin{array}{l}\text { Platelets }<100000 / \mathrm{mm}^{3} \\
\begin{array}{l}\text { Mantoux or Heaf test } \\
\text { negative }\end{array}\end{array}$ & 3 & 1 \\
positive & 14 & 1 \\
\end{tabular}

Conversion: Traditional units to $S I-W B C 10000 / \mathrm{mm}^{3} \approx 10 \times 10^{9} / 1$, Platelets: $100000 / \mathrm{mm}^{3} \approx 100 \times 10^{9} / 1$.

histological picture was of varying numbers of histiocytes with eosinophils, plasma cells, lymphocytes, and polymorphs, so that the label "compatible with histiocytosis $X$ ' was the histological report given. Biopsy was not performed on 5 children. In 2 it was considered too dangerous to biopsy a lesion in the first lumbar vertebra; in 2 bone lesions, thought to be single on clinical examination and with typical features of eosinophilic granuloma on $x$-ray, were associated with the discovery of other bone lesions on skeletal survey, and one child presented with anaemia, purpura, hepatosplenomegaly, and a lesion in the humerus going on to develop pulmonary infiltration, diabetes insipidus, and later short stature.

Biopsy or necropsy material was obtained from 13 of the deaths. In 11 children, histiocytic proliferation with lesser numbers of eosinophils was the predominant finding, and in 2 cases eosinophils were the dominant cells in the specimen. 10 children had necropsies and $\mathbf{8}$ of them had evidence of major lung disease, often with terminal dilatation of the right side of the heart. Emphysematous changes were present in 6 , and 2 had solid lungs with small subpleural areas of infiltration. 3 patients had large mediastinal glands and 1 had biliary cirrhosis. Granulomatous infiltration could be detected on microscopy in many organs, including the tonsils, thymus, pancreas, lungs, liver, spleen, lymph nodes, heart muscle, bone, pituitary, and gut. 3 of the 4 children with diabetes insipidus had necropsy evidence of pituitary or infundibular involvement by a granulomatous process.

One child died elsewhere and details of necropsy findings are not available, though it seems that death was due to the effects of vincristine. The remaining necropsy on a $25 \frac{1}{2}$-year-old male who committed suicide showed no abnormality except for a meningioma near the pituitary fossa.

The one patient who had no biopsy or necropsy proof was a 10-month-old male who presented in
1955 with a discharging right ear and a postaural mass on that side, a cough, fever, cervical lymphadenopathy, hepatosplenomegaly, a maculopapular and, in places, petechial rash, a raised white cell count of $23000 / \mathrm{mm}^{3}\left(23 \times 10^{9} / \mathrm{l}\right)$ and $\mathrm{Hb} 10 \mathrm{~g} / \mathrm{dl}$. Mantoux testing was negative and a chest $x$-ray showed changes suggestive of extensive consolidation.

Diabetes insipidus. 14 patients developed diabetes insipidus and 4 died. 2 of the survivors had temporary diabetes insipidus, one settling without treatment in under 2 months and one needing pitressin for 21 months. Histiocytosis $\mathrm{X}$ began before the age of 1 year in one child who later developed diabetes insipidus, began at age 9 years in one child, and in the rest began between the ages of 1 and 6 years. There was a delay of less than 6 months between onset of histiocytosis $X$ and the onset of diabetes insipidus in 3 children, 13-24 months in 6 children and 2 to 4 years in 4 children. One boy has been lost to follow-up and the age of onset of diabetes insipidus is unknown. 9 children had lesions of the skull vault or base, and 2 had solitary lesions in the mandible. Single lesions in the lumbar spine and tibia occurred in 2 patients, and 1 who died had no detectable bone lesions.

Growth. At some time during the course of their illnesses the weight of 9 of the survivors fell below the 3rd centile. Height also fell below the 3rd centile in 9 survivors.

Treatment. Table 6 shows the main types of treatment used. Surgery consisted of the removal of

Table 6 Main types of treatment

\begin{tabular}{lcc}
\hline & Survivors (29) & Deaths (14) \\
\hline Antibiotics & 13 & 11 \\
Surgery & 5 & 0 \\
Pitressin or lysine vasopressin & 9 & 3 \\
Corticosteroids & 6 & $3^{*}$ \\
Cytotoxics & 1 & 1 \\
$\quad$ Vincristine & 1 & - \\
$\quad$ Chlorambucil & 20 & 5 \\
\hline
\end{tabular}

*2 only terminally.

frontal bone lesions in 3 children, with the insertion of an acrylic plate in 1, mastoid exploration in 1 , and bone grafting in another. Pain relief from radiotherapy was usually good and lesions stopped growing in size, but the start of healing on radiological examination was often delayed for several months. Radiotherapy in those who died was again used for pain relief, as well as to shrink large gland 
masses, lessen proptosis, and attempt to slow the progression of pulmonary infiltration.

Follow-up study. One of the survivors has been completely lost to follow-up. Recent information is available on 26 of the remaining 28 patients. The other 2 are known to be alive and one was followedup until 3 years ago. Of the 26 patients with up-todate information, 14 were seen personally, 4 replied to questionnaires, 2 were not approached directly at the request of the consultant concerned with their care, and 6 were followed up using information from more distant hospitals and general practitioners.

Table 7 shows the medical problems which remain

Table 7 Residual medical problems after histiocytosis $X$

\begin{tabular}{ll}
\hline Complaint & No. of sufferers \\
\hline Diabetes insipidus & $7 *$ \\
Height below 3rd centile & 6 \\
Shortness of breath on effort & 2 \\
Pancytopenia & 1 \\
Recurrent bone lesions & 1 \\
Recurrent lymphadenopathy & 1 \\
Hypogonadism & 1 \\
Limp & 1 \\
Conditions possibly unrelated to histiocytosis & \\
Low IQ & 3 \\
Epilepsy & 1 \\
Duodenal ulcer & 1 \\
Eczema and asthma & 1 \\
No complaints & 14 \\
\hline
\end{tabular}

*The patient who has been lost to follow-up also had diabetes insipidus.

in these 28 patients. Pancytopenia has persisted in one child for 7 years and requires top-up transfusions from time to time. Overall $50 \%$ of those followed up have persisting problems. Only one of these has illness (asthma and eczema) completely unrelated to histiocytosis $\mathrm{X}$. The other possibly unrelated conditions affect patients already with other posthistiocytic problems. In spite of this, all but 3 patients considered themselves or were considered by their parents to be 'well'.

Twenty patients are now over the age of 12 years and 7 are still at school. 2 of these, both of whom had frontal skull bone lesions, are doing well academically, and of the remainder, 3 are thought to be having no problems at school and 2 are described as 'slow'. Of the remaining 13 in this group of older people, 3 are unemployed because of low IQ and one is unemployed because of physical handicap. The remainder have all been able to work. Apart from occasional analgesics, therapy for diabetes insipidus where necessary, and anticonvulsants for epilepsy, the only other regular treatment is testosterone, taken by one male patient with hypogonadism.
Puberty. 8 females whose illnesses began between the ages of 14 months and 9 years (mean $3 \cdot 2$ years) reached menarche between the ages of 11 and 17 years (mean 13.9 years). 3 others have not yet menstruated at the ages of 12,13 , and 13 years. 6 males are known to have passed puberty and are now aged between 18 and 26 years. Puberty is well advanced in one 11-year-old boy, and one shows no signs of puberty at the age of 13 years. Details are not known for the other males. 6 patients have married. 2 females have had children, and one male is the father of a child. Only one male patient has needed testosterone therapy for hypogonadism.

Growth. 5 patients, now aged 17 years or more, from the total group of 28 on whom follow-up information was available, have heights below the 3rd centile. 3 of these have been investigated in the past for growth hormone deficiency; in none was the growth hormone response to hypoglycaemia normal. One of these patients was given growth hormone replacement therapy at the age of 19 years for 12 months without benefit.

Personal follow-up. 14 patients were seen personally and, of these, 12 agreed to have more detailed investigations. Illness had begun at a mean age of $4 \frac{1}{2}$ years (range 14 months- 10 years) and the mean age at follow-up was 17 years (range 10-26 years). All of these had biopsy proof of histiocytosis X initially, and had suffered disease of varying degrees of severity. 6 patients had a solitary bone lesion as their only abnormality and 6 had multiple bone lesions. 3 had splenomegaly, 2 hepatomegaly, and 2 lymphadenopathy at some stage during their illness. 4 patients had developed diabetes insipidus, one of them only transiently. 6 patients had white blood cell counts of $10000 / \mathrm{mm}^{3}\left(10 \times 10^{9} / 1\right)$ or more, and 2 had $\mathrm{Hb}$ levels of $10 \mathrm{~g} / \mathrm{dl}$ or less at some stage in their illness.

On follow-up testing, no patient had $\mathrm{Hb}$ below $12 \mathrm{~g} / \mathrm{dl}$, or white cell count over $10000 / \mathrm{mm}^{3}$ $\left(10 \times 10^{9} / 1\right)$. In all patients total serum protein levels and serum albumin levels were normal. Electrophoretic strips showed slightly increased $\alpha_{2}$-globulin levels in 7 patients, increased $\beta$-globulin in one, and increased $\gamma$-globulin in one. 4 patients had individual immunoglobulin levels (IgM, IgG, IgA) just above or below the normal range for their ages.

Lymphocyte function tests on 7 patients, using phytohaemagglutinin in 7, Concanavallin $A$ in 4 , and pokeweed in 4, gave results within normal limits (Professor J. J. T. Owen). HLA typing was performed on all 12 patients, and compared with the HLA frequences in 150 controls; the frequencies of the antigens in the two groups were very similar 
(Dr. D. Roberts). Because of a recent report (Scott et al., 1975) that opsonization was abnormal in a child who, on histological examination, had LettererSiwe disease, yeast opsonization studies were performed on 11 patients and all samples gave normal results (Professor J. F. Soothill). During their acute illness 5 patients had shown abnormalities on chest $x$-ray; 3 had shown diffuse infiltration and later fibrosis, with 'honeycombing' in 1,1 had increased basal markings, and 1 widespread miliary shadowing. 6 of the remaining 7 had no abnormality on early $x$-rays and one did not have a chest $x$-ray at any stage. Review $x$-rays at the time of follow-up on 11 patients were reported as normal in 9 , as showing overinflation in an asthmatic girl, and showing increased markings in the patient who had earlier shown 'honeycombing'.

Lung function studies were performed on 11 patients (Dr. G. Leathart). One patient showed a diminished vital capacity. In 3 patients the forced expiratory volume in one second was below the normal range, and in 2 of these patients was associated with a history of shortness of breath on effort, in 1 due to asthma and 1 to residual damage from histiocytosis $X$. In the same 3 patients the peak expiratory flow rate was reduced to less than $80 \%$ of the mean normal for age and height. A mild carbon monoxide diffusion defect was present in $\mathbf{4}$ patients and levels at the lower limit of normal were obtained in a further 3 , these 3 having in the past had a normal chest $x$-ray and a solitary bone lesion clinically. 2 other patients with normal chest $x$-rays and a single bone lesion had normal values, as did one child who had been treated with prednisone and vincristine for widespread disease, including pulmonary infiltration.

\section{Discussion}

Although many authors have accepted that LettererSiwe disease, Hand-Schüller-Christian disease, and eosinophilic granuloma of bone can be grouped together under the unifying title of histiocytosis $\mathrm{X}$, as suggested by Lichtenstein (1953), this acceptance is not universal and even as long ago as 1949 , Siwe regarded the similarities of the three conditions as due to enforced similarity of reaction of the reticuloendothelial system to different influences. Clinical Letterer-Siwe disease can be caused by an unusual reaction to viral infection in the immunologically deficient child (Claman et al., 1970), and can be associated with a familial opsonization defect (Scott et al., 1975). For the purpose of this clinical description, I have accepted that Letterer-Siwe disease, Hand-Schüller-Christian disease, and eosinophilic granuloma of bone are related conditions, as cases have been described in which movement from the category of eosinophilic granuloma to HandSchüller-Christian disease and even from eosinophilic granuloma to Letterer-Siwe disease occurred (Dutt et al., 1969).

In such a rare condition it is difficult to arrive at any very accurate estimate of incidence. Cheyne (1971) calculated in his study of 34 cases of all ages that histiocytosis X occurred in about 1 in 2000000 of the population per year in the Bristol clinical area. By adjustment of the under 15-year-old population figures for the area in the current study, as given in the census reports of 1951, 1961, and 1971, one case of histiocytosis X can be expected per 350000 children under the age of 12 years based on 41 locally occurring cases only.

Oberman (1961) found that the presence of focal or widespread bone and soft tissue lesions as prognostic indicators was valuable, and Henderson (1969) used this system in her review of histiocytosis $X$ in Australia. In 1962, Lahey reported that the presence of clinical involvement of soft tissues, i.e. pulmonary lesions, hepatosplenomegaly, and marrow disease as evidenced by anaemia, leucopenia, or thrombocytopenia, was associated with a poor prognosis, as was onset of the disease during the first 3 years of life. $70 \%$ of the children below 6 months of age at onset in his series died, and $50 \%$ of those with an onset before the age of 3 years. A scoring system was suggested as a useful means of assessing the severity in an individual case. This has not been attempted in the present study, which depended almost entirely on review of clinical notes for early features. However, the general observations of Lahey remain true in experience with histiocytosis $\mathrm{X}$ in the north-east of England; that is, the earlier in life that the illness presents the worse the outcome, and the development at some stage of the illness of soft tissue involvement is associated with a worse prognosis.

Bray (1974) has suggested a modification of the Lahey scoring system, and Lahey himself has recently looked in detail at the prognostic value of liver, lung, or haemopoietic dysfunction and found them to be useful (Lahey, 1975a). Newton and Hamoudi (1973), and Lahey (1975a) have also reported that histological appearances can differentiate the more benign types of illness from the more malignant, the former having mixtures of eosinophils and histiocytes and the latter, diffuse histiocytic infiltration. Review of the histological reports relating to the current study suggest that the histological differentiation into 'benign' and 'malignant' disease was not quite as clear cut as this, but several different pathologists did the reporting over the study period.

The main forms of treatment at the present time 
are local surgery, radiotherapy, corticosteroids, and cytotoxic drugs. However, there are well documented cases of extensive disease, particularly of the HandSchüller-Christian or multiple eosinophilic granuloma type, having settled spontaneously after several years. Indeed one child in the present series had multiple bone lesions which came and went over several years from the age of 16 months, and were associated with pulmonary infiltration. Local radiotherapy was given to a few local bone lesions, the disease then settled spontaneously and the patient is alive and well aged 25. Antibiotics were given to many patients during their illness but with no good evidence of a response. Siwe in 1949 stated that in some cases of acute nonlipoid reticuloendotheliosis, a definite infection could be shown as the aetiological agent, and he mentioned a case in which histoplasma was the cause. In at least one biopsy specimen from the present series, Gram-positive cocci were visible on histological examination.

Excluding patients with solitary eosinophilic granulomas, Lahey (1975b) has recently reported a comparative trial of three different treatment regimens using corticosteroids and cytotoxic drugs. $71 \%$ of his cases have survived from the onset of therapy for 6 months to 6 years with a mean of about $3 \frac{1}{2}$ years. It is noteworthy in this present series that few patients had corticosteroids or cytotoxic drugs, but one died of the side effects of vincristine.

In this series $67 \%$ have survived so far and the group includes patients with disease of all degrees of severity. The fact that most of the cases of extensive disease in this present series had their illnesses and died 20 years or more before the advent of corticosteroid or cytotoxic therapy has probably contributed to a worse survival rate.

The percentage of patients having detectable disability after histiocytosis $X$ is high $(54 \%)$. Lahey (1975b) reported that, excluding eosinophilic granuloma of bone, $63 \%$ of 59 patients had disability in the form of chronic active disease, small stature, diabetes insipidus, exophthalmos, vertebral compression, or $x$-ray evidence of lung fibrosis.

Several patients in the present series have an adult height below the 3rd centile and there is now good evidence that this is due in large part to growth hormone deficiency, though in one of the cases in the north-east of England the shortness was added to by collapse of several vertebrae secondary to prolonged treatment with corticosteroids. The satisfactory response of 5 patients with growth retardation due to Hand-Schüller-Christian disease when treated with human growth hormone has been recently reported (Braunstein et al., 1975).

Eosinophilic granuloma affecting the lung is a recognized entity (Lewis, 1971) and on recovery any residual fibrosis may affect carbon monoxide diffusing capacity. It is, however, of interest that 3 patients in this series, with what was clinically a solitary bone lesion and a normal chest $x$-ray at the time of their illness, should have carbon monoxide diffusing capacities at the lower limit of normal. This suggests that even apparently solitary granulomas in bone may not in fact be the only lesions present. Lewis (1964) made the point that in older patients with eosinophilic granuloma of the lungs, there may be dyspnoea, but the chest $x$-ray be regarded as normal unless repeated after a period of time or with altered penetration.

The cause of histiocytosis $\mathrm{X}$ remains unknown. As mentioned above, some cases have been associated with immunological disorders. The patients in this series who had simple tests of lymphocyte function performed and yeast opsonization studies after recovery showed no abnormality. A more detailed study of immunological findings in histiocytosis $\mathrm{X}$ using tests of lymphocyte and neutrophil function and immunoglobulin levels showed that immunological abnormalities could be shown during the active illness, but there was no evidence of a combined immunodeficiency disorder (Leikin et al., 1973). These authors felt that the immunological abnormalities found were not the cause of the illness but were secondary to malignant cell replacement.

HLA typing seems to be unhelpful in the detection of a group of children who might be at risk from this disease. It is interesting that many of the severe cases occurred in the early post-war years. Nutritional inadequacies at that time possibly played a part in creating this situation.

Very careful assessment of all body systems is needed to assess accurately the state of dissemination of the disease in any one case, as the use of staging does help in assessing prognosis. An investigation protocol has recently been suggested by Nesbit and Krivit (1976). In such an uncommon condition it is essential that, while the newer types of therapy are being assessed and attempts made to determine the cause of the disease, all cases are very accurately documented and treatment controlled by a major centre. Only then can valid comparisons of mortality rates and residual disability on different treatment regimens be made.

I am grateful to the many general practitioners and consultants who helped supply information for this study and let me see their patients; to Dr. G. Leathart, Professor J. J. T. Owen, Dr. D. Roberts, and Professor J. F. Soothill for supplying special 
laboratory data; to Professors S. D. M. Court and J. K. G. Webb for their help; and to Miss Jill TreeceBirch for secretarial assistance.

\section{References}

Braunstein, G. D., Raiti, S., Hansen, J. W., and Kohler, P. O. (1975). Response of growth-retarded patients with Hand-Schüller-Christian disease to growth hormone therapy. New England Journal of Medicine, 292, 332-333.

Bray, P. T. (1974). Histiocytosis-X. Malignant Diseases in Children, Chap. 19. Ed. by T. J. Deeley. Butterworths, London.

Cheyne, C. (1971). Histiocytosis X. Journal of Bone and Joint Surgery, 53B, 366-382.

Claman, H. N., Suvatte, V., Githens, J. H., and Hathaway, W. E. (1970). Histiocytic reaction in dysgammaglobulinaemia and congenital rubella. Pediatrics, 46, 89-96.

Dutt, A. K., Lopez, C. G., Ganesan, S., and Dutt, A. (1969). Acute disseminated histiocytosis $\mathbf{X}$. A case with transition from eosinophilic granuloma of bone to Letterer-Siwe disease. Australasian Annals of Medicine, 18, 135-137.

Henderson, J. I. (1969). Histiocytic reticulosis. A review of twenty patients in the paediatric age range. Medical Journal of Australia, 2, 485-490.

Lahey, M. E. (1962). Prognosis in reticuloendotheliosis in children. Journal of Pediatrics, 60, 664-671.

Lahey, M. E. (1975a). Histiocytosis X-an analysis of prognostic factors. Journal of Pediatrics, 87, 184-189.

Lahey, M. E. (1975b). Histiocytosis X-comparison of three treatment regimens. Journal of Pediatrics, 87, 179-183.

Leikin, S., Peruganan, G., Frankel, A., Steerman, R., and Chandra, R. (1973). Immunological parameters in histiocytosis X. Cancer, 32, 796-802.
Lewis, J. G. (1964). Eosinophilic granuloma and its variants with special reference to lung involvement. Quarterly Journal of Medicine, 33, 337-358.

Lewis, J. G. (1971). Pulmonary manifestations of histiocytosis X. Proceedings of the Royal Society of Medicine, 64, 338-340.

Lichtenstein, L. (1953). Histiocytosis X. Integration of eosinophilic granuloma of bone, 'Letterer-Siwe disease' and 'Schüller-Christian disease' as related manifestations of a single nosologic entity. Archives of Pathology, 56, 84-102.

Nesbit, M. E., and Krivit, W. (1976). Histiocytosis. Cancer in Children, Clinical Management, p. 194. Ed. by H. J. G. Bloom, J. Lemerle, M. K. Neidhardt, and P. A. Voute. Springer, Berlin.

Newton, W. A., and Hamoudi, A. B. (1973). Histiocytosis-a histological classification with clinical correlation. Perspectives in Pediatric Pathology, Vol. 1, pp. 251-283. Year Book Medical Publishers, Chicago.

Oberman, H. A. (1961). Idiopathic histiocytosis. A clinicopathological study of 40 cases and review of the literature on eosinophilic granuloma of bone, Hand-SchüllerChristian disease and Letterer-Siwe disease. Pediatrics, 28, 307-327.

Scott, H., Moynahan, E. J., Risdon, R. A., Harvey, B. A. M. and Soothill, J. F. (1975). Familial opsonization defect associated with fatal infantile dermatitis, infections, and histiocytosis. Archives of Disease in Childhood, 50, 311-317.

Siwe, S. (1949). The reticuloendothelioses in children. Advances in Pediatrics, Vol. 4, p. 117. Interscience Publishers, New York.

Correspondence to Dr. D. G. Sims, Booth Hall Children's Hospital, Charlestown Road, Blackley, Manchester M9 ZAA. 